\title{
Lumbar puncture in patients using anticoagulants and antiplatelet agents
}

\author{
Punção lombar em pacientes usando anticoagulantes e agentes antiplaquetários \\ Renan Domingues ${ }^{1}$, Gustavo Bruniera ${ }^{1,2}$, Fernando Brunale ${ }^{1,2}$, Cristóvão Mangueira' ${ }^{2}$, Carlos Senne ${ }^{1,2}$
}

\begin{abstract}
The use of anticoagulants and antiplatelet agents has largely increased. Diagnostic lumbar puncture in patients taking these drugs represents a challenge considering the opposing risks of bleeding and thrombotic complications. To date there are no controlled trials, specific guidelines, nor clear recommendations in this area. In the present review we make some recommendations about lumbar puncture in patients using these drugs. Our recommendations take into consideration the pharmacology of these drugs, the thrombotic risk according to the underlying disease, and the urgency in cerebrospinal fluid analysis. Evaluating such information and a rigorous monitoring of neurological symptoms after lumbar puncture are crucial to minimize the risk of hemorrhage associated neurological deficits. An individualized patient decision-making and an effective communication between the assistant physician and the responsible for conducting the lumbar puncture are essential to minimize potential risks.
\end{abstract}

Keywords: anticoagulants; platelet aggregation inhibitors; spinal puncture; hematoma, spinal.

\section{RESUMO}

O uso de anticoagulantes e de agentes antiplaquetários tem aumentado nos últimos anos. A realização de punção lombar diagnóstica em pacientes utilizando tais medicamentos representa um desafio, em função dos riscos de complicações hemorrágicas ou trombóticas, estas últimas em pacientes que interrompem o tratamento para a realização do procedimento. Não há ainda estudos controlados nem diretrizes específicas nesta área. Neste artigo de revisão, algumas recomendações são feitas, levando-se em conta aspectos farmacológicos destas medicações, o risco de complicações trombóticas de acordo com a doença de base, e a urgência na coleta do líquor. A avaliação cuidadosa destas informações e uma monitorização neurológica rigorosa visando a detecção e o tratamento precoce de complicações podem reduzir o risco de sequelas neurológicas decorrentes de hemorragia. Uma decisão individualizada e uma efetiva comunicação entre o médico assistente e o responsável pela realização da punção lombar é essencial para minimizar potenciais riscos.

Palavras-chave: anticoagulantes; inibidores da agregação de plaquetas; punção espinal; hematoma espinhal.

Lumbar puncture (LP) is the most used technique for obtaining cerebrospinal fluid (CSF). CSF analysis is crucial in the diagnosis of a variety of infectious and noninfectious neurologic conditions ${ }^{1}$. LP is a relatively safe procedure, but complications such as post-LP headache, infection, and bleeding may occur. Minor bleeding is characterized by the presence of red blood cells in the CSF. Spinal hematoma is a rare complication but its risk increases in patients with any bleeding predisposing condition. Spinal hematoma presents with back pain and neurologic findings such as weakness, reduced sensation, and incontinence ${ }^{2}$. The true incidence of hemorrhagic complications associated with diagnostic LP is unknown, but it is estimated to be less than $1 / 220,000$ for spinal anesthetics ${ }^{3}$.

The use of anticoagulants and antiplatelet agents has grown $n^{4,5,6}$ due to the aging of the population and the availability of a wider range of drugs for prevention and treatment of vascular diseases ${ }^{7,8}$. Patients using these drugs have increased risk of bleeding complications when submitted to LP. Neurologists and other physicians that order and/or perform spinal tap should be aware of that and should carefully evaluate the risks and benefits of maintaining or discontinuing the medication prior LP.

There are not many studies examining the risk of bleeding after LP in patients using anticoagulants and antiplatelet agents. Clear recommendations are lacking in this regard. Three issues have to be considered when a physician is faced with a patient in need of a LP and using one or some of these drugs. It is possible to reduce bleeding risk by discontinuing or reversing the effect of these drugs. In the other hand it is crucial to take into account the increased thrombotic risk

'Senne Líquor Diagnóstico, São Paulo SP, Brasil;

${ }^{2}$ Hospital Israelita Albert Einstein, Laboratório de Patologia Clínica, São Paulo SP, Brasil.

Correspondence: Renan Domingues; Senne Líquor Diagnóstico; Rua Maestro Cardim, 560 / sala 2; $01323-001$ São Paulo SP, Brasil; E-mail: contato@ renandomingues.med.br

Conflict of interest: There is no conflict of interest to declare.

Received 20 January 2016; Accepted 25 May 2016. 
associated with this discontinuation. It is also important to consider that in many instances, in which CSF analysis is an emergence, it is not possible to wait for the reversal of pharmacological effects of such drugs.

In this critical review we discuss the risk of LP associated bleeding in patients using anticoagulants and antiplatelet agents and make some practical recommendations taking into account these three major issues.

\section{ORAL ANTIPLATELET TREATMENTS}

Oral antiplatelet agents comprise a group of drugs that interfere with the formation of thrombi on atherosclerotic plaques. Antiplatelet agents are effective in reducing the risk of diseases such as myocardial infarction, ischemic stroke, and peripheral arterial disease ${ }^{\text {. }}$.

\section{Aspirin}

Aspirin (acetylsalicylic acid) is the most used antiplatelet drug worldwide ${ }^{10}$. Aspirin is largely used in the prevention of coronary disease, stroke, and peripheral vascular disease.

Patients in use of aspirin have an increased risk of bleeding $^{11}$. The spinal tap bleeding risk in patients using aspirin has been studied. One case report showed spinal subdural hematoma in a patient submitted to LP using aspirin ${ }^{12,13}$. In a prospective study, Horlocker et cols. evaluated the data of 924 patients given spinal or epidural anesthesia. Among those patients 193 were using aspirin. None out of these patients had major hemorrhagic complications and 47 (24.4\%) had minor hemorrhagic complications ${ }^{14}$, suggesting a very low LP associated major bleeding risk associated with aspirin. In the other hand there is a considerable risk of vascular complications among patients in which aspirin is discontinued. In a previous study this risk was estimated to be $10.2 \%{ }^{15}$.

Given the low risk of bleeding associated with its use and the high risk of ischemic complications associated with aspirin interruption, we propose that aspirin is not interrupted for performing LP.

\section{Thienopyridines}

Ticlopidine, clopidogrel, and the more recently introduced plasugrel are ADP platelet receptor inhibitors widely used for acute coronary syndromes, after stent placement, and more rarely for secondary prevention of cerebrovascular and peripheral ischemia ${ }^{16,17,18}$. Clopidogrel is frequently used in the form of dual antiplatelet therapy, which consists in combination of aspirin and clopidogrel ${ }^{19}$.

The risk of bleeding after diagnostic and therapeutic procedures increases with the use of these drugs, and this increased risk persists for a few days after cessation of these drugs. After complete interruption the clopidogrel effect lasts from 5 to 7 days, ticlopidine from 10 to 14 days, and plasugrel from 7 to 9 days ${ }^{20}$.
There is little information on LP associated bleeding risk in patients using thyenopyridines. Some studies assessed the clopidogrel associated bleeding risk in patients submitted to spinal anesthesia and other medical procedures. In general, these studies showed a low clopidogrel associated bleeding risk $^{21,22,23,24,25}$. However, this risk is higher and potentially serious in patients using clopidogrel in combination with aspirin. Paal and cols. described a case of subarachnoid hemorrhage after a diagnostic LP performed with a fine needle in a patient using aspirin and clopidogrel ${ }^{26}$.

In view of this risk the American Society of Regional Anesthesia (ASRA) proposed that clopidogrel should be discontinued for 7 days before spinal anesthesia ${ }^{27}$. On the other hand, it is well known that clopidogrel discontinuation may be associated with increased risk of ischemic events in high-risk patients $^{16,17,18}$. Therefore, the decision must be individualized taking into consideration the thrombotic risk and the urgency in CSF analysis. In patients with high cardio or cerebrovascular risk, for instance, in a patient with recent stent placement, we propose that LP should be done regardless the use of clopidogrel. We also recommend not discontinuing thyenopyridine when CSF analysis is urgent for diagnosing a potentially serious and acute CNS disease. Thyenopyridine may be interrupted for an elective LP in a patient with low cardiovascular and cerebrovascular ischemic risk. In those cases aspirin, which is associated with a lower risk of bleeding, can be used (Table 1).

\section{HEPARIN}

Heparin and its derivates are often used for prevention and treatment of venous thrombosis, myocardial infarction, and unstable angina ${ }^{28,29}$.

Table 1. Recommendation for performing lumbar puncture (LP) in patients treated with antiplatelet agents.

\section{Aspirin $\circledast$}

Do not discontinue aspirin for performing LP

Clopidogrel or dual antiplatelet therapy

High thrombotic risk

Emergency $L P$ - Perform LP

Elective LP - Continue antiplatelet therapy.

If clopidogrel is given alone consider replace clopidogrel by aspirin and perform LP one week after replacement.

If dual therapy is being used continue it and consider postponing $\mathrm{LP}$ and perform it when aspirin alone is possible.

Low thrombotic risk

Emergency $L P$ - Perform LP

Elective LP

If clopidogrel is used alone consider discontinuing clopidogrel and performing LP one week after discontinuation.

If dual therapy is used, keep aspirin alone and perform LP one week after clopidogrel discontinuation 


\section{Intravenous therapeutic heparin}

Intravenous heparin was shown to be associated with a high risk of spinal bleeding in patients submitted to $\mathrm{LP}^{30,31,32}$. Therefore, this procedure should not be carried out in patients using heparin.

The half-life of intravenous heparin ranges from 30 to 150 minutes and its effect can be safely monitored by activated partial thromboplastin time $(\mathrm{aPTT})^{28,29}$. In view of the short half-life of intravenous heparin we propose that heparin should always be interrupted and LP should be performed at least 4 hours after the time of heparin interruption. Alternatively, LP could be carried out when aPTT is in the normal range (Table 2). A prospective study evaluating the heparin associated bleeding risk after LP showed a higher risk of major bleeding complications if heparin is given less than 1 hour after $\mathrm{LP}^{30,31}$; therefore, heparin may be restarted after 1 hour after LP.

\section{Subcutaneous unfractioned heparin}

Subcutaneous heparin is used for deep venous thrombosis prevention. aPTT is not usually changed in patients using low-dose subcutaneous unfractioned heparin ${ }^{29}$. The half-life of subcutaneous heparin ranges from 1.5 to 6 hours.

The risk of hemorrhagic complication after LP in patients using subcutaneous heparin is lower than with intravenous heparin; however, complications were previously reported, such as subarachnoid hematoma and spinal cord injury ${ }^{32,33,34}$.

We recommend spinal tap should be carried out at least 6 hours after the last injection of subcutaneous heparin. This approach is safe considering the short half-live of this drug. Bleeding complications, although rare with this drug, may occur and can be prevented with a little delay in carrying out the puncture.

\section{Low molecular weight (LMW) heparin}

LMW is currently the most used option for prophylaxis of venous thrombosis. The aPTT is not affected by LMW heparin. The half-life of LMW heparin is somewhat longer than subcutaneous unfractioned heparin, ranging from 4 to

Table 2. Recommendation for performing lumbar puncture (LP) in patients treated with injectable anticoagulants.

Intravenous heparin
Perform LP 4 hours after heparin discontinuation or after aPTT
is in the normal range
Unfractioned subcutaneous heparin
Perform LP $4-6$ hours after the last dose of subcutaneous
heparin
Subcutaneous LMW heparin
Perform LP after 12 hours after the last dose of LMW heparin.
In patients with renal insufficiency and in patients using
therapeutic doses of enoxaparin this time should be prolonged
to 24 hours

LMW: low molecular weight; aPTT: activated partial thromboplastin time.
7 hours ${ }^{29,34}$. Unlike the other heparins, the drug elimination of LMW heparin is affected by renal insufficiency and the half-life can be extended to nearly 16 hours ${ }^{35}$.

It was previously estimated that the risk of LP associated spinal hematoma in patients receiving LMW ranges from 1:10000 to $1: 1000^{36,37}$. The concomitant use of antiplatelet agents and a traumatic spinal tap could increase that risk ${ }^{36}$.

In view of the pharmacology of this drug we recommend a minimum interval of 12 hours between the last dose of LMW heparin and LP. In patients with renal impairment and in patients using therapeutic doses of enoxaparin this interval should be of at least 24 hours ${ }^{36,37,38}$. This recommendation is particularly important for hospitalized patients because a great number of them receive LMW heparin for the prevention of deep venous thrombosis. In this population the precise time of the last dose of LMW heparin should be carefully verified before LP.

\section{ORAL ANTICOAGULANTS}

Oral anticoagulants use is growing. As they significantly increase the risk of bleeding, performing LP in anticoagulated represents a challenge. In contrast to heparin and its derivates, oral anticoagulants have longer half-lives. This represents a problem since a longer period of drug suspension would be necessary to reduce bleeding risk, exposing patients to increased thrombotic risk during the interruption period. Thus, an individualized approach should be adopted according to the anticoagulant used and the characteristics of the patient.

\section{Warfarin}

Warfarin is a vitamin- $\mathrm{K}$ antagonist with an anticoagulant effect through the inhibition of several coagulation proteins. There are several indications for the use of this drug, such as post-operative states, deep venous thrombosis, atrial fibrillation, and prosthetic heart valves. The warfarin dose is adjusted according with the international normalized ratio (INR), a monitoring index based on pro-thrombin time (PT). Hemorrhage is an important adverse effect of warfarin. This risk is higher with higher INR values ${ }^{39}$. After the interruption of warfarin the anticoagulant effect lasts for up to five days ${ }^{40}$. The effect of this drug can be pharmacologically reversed with vitamin $\mathrm{K}$, fresh frozen plasma, or prothrombin complex concentrates ${ }^{39}$.

There are several reports of spinal epidural hematoma following LP in patients using warfarin, especially when the INR is of 1.5 or above ${ }^{34,41}$. In view of this risk LP should be postponed until INR is bellow 1.5. In patients requiring prompt LP, warfarin effect reversal should be considered. Vitamin K is the most used therapy to reverse warfarin effect. Low-dose 
prothrombin complex concentrate before LP was previously shown to be a promising option ${ }^{42}$.

The warfarin effect reversal strategies are limited to patients without high-risk of thrombotic events. In high-risk patients one alternative is to temporarily replace warfarin with LMW heparin or unfractioned heparin for at least five days before LP. In patients with impaired renal function the use of unfractioned heparin is preferable, considering that its elimination is not affected by renal insufficiency. These options are restricted to patients with elective spinal tap indication. In patients with a high-risk of thrombosis and requiring prompt CSF analysis it is justifiable to perform LP without reversing warfarin effect (Table 3). Considering the risk of bleeding, strict neurological monitoring after puncture is mandatory in this situation.

\section{New oral anticoagulants (NOACs)}

The NOACs were recently introduced and have several pharmacological advantages compared to warfarin, including not being necessary monitoring its effect by INR and less interaction with other drugs and food. They have been increasingly used for cardioembolic stroke prevention and venous thromboembolism treatment and prevention ${ }^{43}$.

Table 3. Recommendation for performing lumbar puncture (LP) in patients treated with oral anticoagulants.

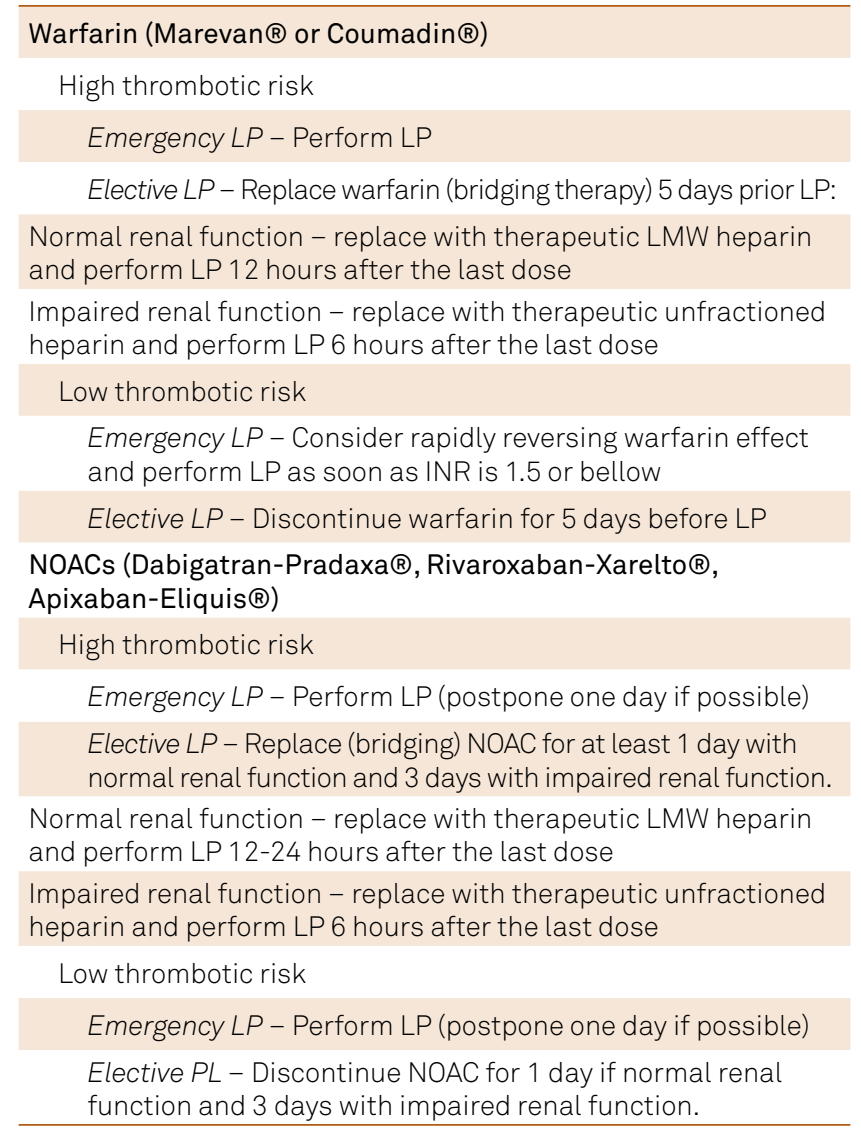

NOACs: new oral anticoagulants; LMW: low molecular weight.

\section{Dabigatran}

Dabigatran is a thrombin inhibitor with a 14-17 hours half-life. Its half-life is prolonged in patients with renal insufficiency reaching up to 28 hours $^{44}$. Seventy five per cent of the drug is eliminated of the body after two half-lives.

Dabigatran has been associated with an increased risk of bleeding, especially in patients concomitantly using antiplatelet agents ${ }^{43}$. There have been some practical recommendations for peri-procedural management of patients receiving this drug ${ }^{45}$. These recommendations are based more on pharmacological aspects of the medication but clinical trials are still missing in this regard. It has been proposed that dabigatran should be discontinued for 1 to 3 days in patients with creatinine clearance $>50 \mathrm{ml}$ min and for 3 to 5 days if $<50 \mathrm{ml} \min ^{46,47,48}$. Considering that spinal tap is a low bleeding risk procedure we recommend that the interval between the last dose of dabigatran and spinal tap is at least of one day for patients with normal renal function and three days for patients with creatinine clearance bellow $50 \mathrm{ml}$ min. In thrombotic high-risk cases with normal renal function we recommend that dabigatran is stopped and replaced for anticoagulant dosage of LMW heparin for 1 day, and spinal tap is performed at least 12 hours after the last dose of LMW heparin. In patients with high-risk of thrombotic events and impaired renal function we propose dabigatran is stopped 3 days before spinal tap and receive anticoagulant dosage of unfractioned heparin during the interval between dabigatran interruption and spinal tap. LP should be carried out at least 6 hours after the last dose of unfractioned heparin. When obtaining CSF is an emergence, LP should be carried out immediately, even though the risk of bleeding (Table 3). Considering the risk of spinal hematoma, a careful neurological observation becomes mandatory in this situation. Based on recommendations carried out for regional anesthesia, this medicine can be safely reintroduced six hours after the diagnostic $\mathrm{LP}^{45}$.

\section{Rivaroxaban}

Rivaroxaban inhibits factor Xa. Rivaroxaban half-life is of 5.7-9.2 hours, but it can reach 11-13 hours in elderly patients with decline in renal function. Anti-factor Xa was previously tested to evaluate rivaroxaban effect; however, as it occurs with other NOACs, no laboratorial evaluation of its effect is routinely performed ${ }^{43,49}$.

Rivaroxaban is associated with increased risk of bleeding, and this risk increases with the association of an antiplatelet agent ${ }^{45}$. Some practical recommendations have been settled for patients undergoing medical procedures. Based on these recommendations rivaroxaban should be discontinued 1 to 2 days before medical procedures in patients with without renal insufficiency, and 3 to 5 days with renal function impairment ${ }^{44,47,48}$.

We propose that the interval between the last dose of rivaroxaban and spinal tap is of at least one day for patients with normal renal function and three days with impaired renal function. The thrombotic risk has to be carefully evaluated before drug interruption. If a high thrombotic risk exists and the 
renal function is normal a substitution of rivaroxaban for LMW heparin for at least one day should be carried out and LP performed 12 hours after the last LMW heparin dose. In high-risk patients with impaired renal function rivaroxaban should be replaced by anticoagulant dosage of unfractioned heparin for at least 3 days. LP should be performed at least 6 hours after the last unfractioned heparin dose (Table 3). When an emergence CSF analysis is required, spinal tap can be carried out without prior interruption and/or replacement with close monitoring of neurological signs. Reasumption of this drug can de done 5.5 hours after diagnostic $\mathrm{LP}^{45}$.

\section{Apixaban}

Apixaban is a factor Xa inhibitor. Its half-life is about 12 hours. The elimination of the drug is renal and fecal. As for other NOACs, apixaban is not monitored by INR. Anti-Xa assay measures its activity but this test is not routinely used ${ }^{50}$.

Practical recommendations based on pharmacological aspects of the drug have been proposed. It was suggested that apixaban should be interrupted 1-2 days before medical procedures in patients with normal renal function and 3 to 5 days if the creatinine clearance is bellow $50 \mathrm{ml} \mathrm{min} \mathrm{mb}^{46,48}$.

We propose a time interval between drug interruption and spinal tap is of at least one day when renal function is normal and three days with impaired renal function. As for other anticoagulants, the interruption decision should take into account the thrombotic risk. When there is a high thrombotic risk patient we propose a replacement/bridging therapy instead of an interruption. The replacement procedure with anticoagulant dosage of LMW heparin or unfractioned heparin should be adopted according to the renal function. The interruption intervals we propose for apixaban are also the same for other NOACs. The same approach proposed for other NOACs regarding emergence CSF analysis should be adopted with this drug (Table 3). Apixaban can be reintroduced 7 hours after the procedure ${ }^{45}$.

\section{ASSESSMENT OF THROMBOTIC RISK}

As we mentioned in previous sections of this article, a crucial step in deciding the drug discontinuation or drug replacement before performing LP is evaluating the thrombotic risk of the patient ${ }^{51}$.

Overall, the thrombotic risk can be low, moderate or high, depending on the underlying disease. In several clinical scenarios, the assessment of thrombotic risk can be done with the use of clinical scales. In patients with non-valvular atrial fibrillation (AF), the stroke risk can be predicted by $\mathrm{CHADS}_{2}$ or $\mathrm{CHA}_{2} \mathrm{DS}_{2}-$ Vasc scores. A detailed description of these scores is beyond the scope of this article, but the higher the scores are higher is the risk of cardioembolic events ${ }^{52}$. Patients with prosthetic heart valves may have low, moderate, and high risk of thrombotic events according to previously proposed parameters ${ }^{53}$.
Patients at high risk of cardio embolism should not discontinue anticoagulants before being submitted to LP. When LP is not an emergency and can be performed a few days later, the use of replacement/bridging anticoagulation before PL should be carried out, according to the schedules mentioned in previous sections and in Table 3.

In patients with venous thromboembolism the risks of thromboembolic complications are higher in the first 3 months after diagnosis use of anticoagulation therapy. Other factors influence the risk of complications, such as the presence of underlying thrombophilia or cancer ${ }^{54}$. Among high-risk patients a drug replacement/bridging with temporary introduction of LMW heparin or unfractioned heparin can be used, whenever LP can be delayed.

Another high-risk situation frequently seen in clinical practice is the use of dual antiplatelet therapy in patients submitted to coronary or carotid stenting. Dual antiplatelet therapy is also efficient in patients with acute coronary syndrome and in patients submitted to transcatheter aortic valve implantation ${ }^{55,56,57,58}$. In these groups the risk of thrombotic complications is high; therefore, dual antiplatelet therapy should not be interrupted, since the risk of cardio and/or cerebrovascular events exceeds the risk of bleeding complications associated with the procedure.

\section{FINAL REMARKS}

LP is a low bleeding risk procedure; however, potentially serious complications, such as spinal hematoma, may occur. The use of antiplatelet and anticoagulant drugs increases the risk of hemorrhagic complication and therefore must be carefully evaluated before performing LP. The thrombotic risk must be considered before deciding on temporary discontinuation of any of these drugs. In patients with higher thrombotic risk, the risk of thrombotic complications outweighs the risk of LP associated hemorrhagic complications. Consequently, it is recommended to do not interrupt antiplatelet and/or anticoagulants. In the other hand, if the thrombotic risk is low, a temporary discontinuation of medication should be considered.

Another relevant point is the emergency in obtaining CSF. For example, in patients with suspected meningitis or Guillain-Barrè syndrome, LP should not be postponed considering the potential morbidity and mortality in these cases. In cases in which the CSF analysis was ordered to investigate a chronic neurological disease, for example, a chronic autoimmune disease, LP can generally be delayed for a few days. A temporary discontinuation of the anticoagulant or antiplatelet drug can be considered in such cases. If the thrombotic risk is high and LP can be postponed a viable alternative is using bridging/replacement therapy. This therapy allows maintaining an adequate level of anticoagulation despite temporary discontinuation of warfarin or NOACs. 
There are some general measures tat can reduce the risk of LP associated bleeding and its complications in patients using these medications. The utilization of small-gauge needles may help to reduce trauma to epidural or subarachnoid vessels ${ }^{3}$. Special attention should be given to patients concomitantly using antiplatelet agents and anticoagulants, which increases the bleeding risk ${ }^{30}$. It is always important to closely monitor the patient after the procedure. If the patient develops severe radicular pain, motor or sensitive deficit, any symptoms of myelitis or cauda equina syndrome, an expeditious investigation of spinal hematoma must be carried out. Prompt surgical intervention may minimize the incidence of permanent serious neurological sequelae if this complication occurs ${ }^{32}$.

The present recommendations are largely based on guidelines elaborated to procedures other than the LP, including surgical procedures and spinal anesthesia. Another limitation of the present review is that most of the cited information consists of case reports, small series, and the pharmacological aspects of anticoagulants and antiplatelet agents. To date, there are not robust evidences guiding LP in these patients, so that further prospective studies are still required.

The assistant physician should always plan LP in accordance with all the mentioned variables. In turn, the physician responsible for carrying out the LP should always carefully check the patient's medications prior to the procedure, noting if any of these medications are being used and the last time of its administration. Whenever necessary it is important to discuss in detail with the assistant physician the risks involved and how to minimize them. The effective communication between the assistant physician and the physician conducting the procedure is crucial. An individualized evaluation of bleeding and thrombotic risk, the emergency of CSF analysis, and a rigorous monitoring of neurological symptoms after the procedure are the key elements to minimize the risks of LP complications among patients using antiplatelet agents and/or anticoagulants.

\section{References}

1. Deisenhammer F, Bartos A, Egg R, Gilhus NE, Giovannoni G, Rauer $S$ et al. Guidelines on routine cerebrospinal fluid analysis. Report from an EFNS task force. Eur J Neurol. 2006;13(9):913-22. doi:10.1111/j.1468-1331.2006.01493.x

2. Lawton MT, Porter RW, Heiserman JE, Jacobowitz R, Sonntag VK, Dickman CA. Surgical management of spinal epidural hematoma: relationship between surgical timing and neurological outcome.J Neurosurg. 1995;83(1):1-7. doi:10.3171/jns.1995.83.1.0001

3. Horlocker TT, Wedel DJ. Anticoagulation and neuraxial block: historical perspective, anesthetic implications, and risk management. Reg Anesth Pain Med. 1998;23(6 Suppl 2):129-34. doi:10.1016/S1098-7339(98)90137-7

4. Büller HR, Prins MH, Lensin AW, Decousus H, Jacobson BF, Minar E et al. Oral rivaroxaban for the treatment of symptomatic pulmonary embolism. N Engl J Med. 2012;366(14):1287-97. doi:10.1056/NEJMoa1113572

5. Ntaios G, Papavasileiou V, Diener HC, Makaritsis K, Michel P. Nonvitamin-K-antagonist oral anticoagulants in patients with atrial fibrillation and previous stroke or transient ischemic attack: a systematic review and meta-analysis of randomized controlled trials. Stroke. 2012;43(12):3298-304. doi:10.1161/STROKEAHA.112.673558

6. Lip GY, Lane DA. Stroke prevention with oral anticoagulation therapy in patients with atrial fibrillation. Circ J. 2013;77(6):1380-8. doi:10.1253/circj.CJ-13-0465

7. Sabatine MS, Cannon CP, Gibson CM, López-Sendón JL, Montalescot $G$, Theroux P et al. Addition of clopidogrel to aspirin and fibrinolytic therapy for myocardial infarction with ST-segment elevation. N Engl J Med. 2005;352(12):1179-89. doi:10.1056/NEJMoa050522

8. Mehta SR, Yusuf S, Peters RJ, Bertrand ME, Lewis BS, Natarajan MK et al. Effects of pretreatment with clopidogrel and aspirin followed by long-term therapy in patients undergoing percutaneous coronary intervention: the PCI-CURE study. Lancet. 2001;358(9281):527-33. doi:10.1016/S0140-6736(01)05701-4

9. Zusman RM, Chesebro JH, Comerota A, Hartmann JR, Massin EK, Raps $E$ et al. Antiplatelet therapy in the prevention of ischemic vascular events: literature review and evidence-based guidelines for drug selection. Clin Cardiol.1999;22(9):559-73. doi:10.1002/clc.4960220905

10. Born G, Patrono C. Antiplatelet drugs. Br J Pharmacol. 2006;147(S1):S241-51. doi:10.1038/sj.bjp.0706401
11. Antiplatelet Trialists' Collaboration Collaborative overview of randomised trials of antiplatelet therapy - I: prevention of death, myocardial infarction, and stroke by prolonged antiplatelet therapy in various categories of patients. BMJ. 1994;308(6921):81-106. doi:10.1136/bmj.308.6921.81

12. Urmey WF, Rowlingson J. Do antiplatelet agents contribute to the development of perioperative spinal hematoma? Reg Anesth Pain Med. 1998;23(6 Suppl 2):146-51. doi:10.1016/S1098-7339(98)90140-7

13. Pryle BJ, Carter JA, Cadoux-Hudson T. Delayed paraplegia following spinal anaesthesia. Spinal subdural haematoma following dural puncture with a $25 \mathrm{G}$ pencil point needle at T12-L1 in a patient taking aspirin. Anaesthesia. 1996;51(3):263-5. doi:10.1111/j.1365-2044.1996.tb13644.x

14. Horlocker TT, Wedel DJ, Schroeder DR, Rose SH, Elliott BA, McGregor $D G$ et al. Preoperative antiplatelet therapy does not increase the risk of spinal hematoma associated with regional anesthesia. Anesth Analg. 1995;80(2):303-9. doi:10.1097/00000539-199502000-00017

15. Hillemacher T, Bleich S, Wiltfang J, Weber M, Kornhuber J, Frieling $\mathrm{H}$. Should aspirin be discontinued for diagnostic lumbar puncture? J Am Geriatr Soc. 2006;54(1):181-2. doi:10.1111/j.1532-5415.2005.00575_12.x

16. Mohammad RA, Goldberg T, Dorsch MP, Cheng JW. Antiplatelet therapy after placement of a drug-eluting stent: a review of efficacy and safety studies. Clin Ther. 2010;32(14):2265-81. doi:10.1016/j.clinthera.2011.01.003

17. Field TS, Benavente OR. Current status of antiplatelet agents to prevent stroke. Curr Neurol Neurosci Rep. 2011;11(1):6-14. doi:10.1007/s11910-010-0162-y

18. Wiviott SD, Steg PG. Clinical evidence for oral antiplatelet therapy in acute coronary syndromes. Lancet. 2015;386(9990):292-302. doi:10.1016/S0140-6736(15)60213-6

19. Carreras ET, Mega JL. Dual antiplatelet therapy for heart disease. Circulation. 2014;129(21):e506-8. doi:10.1161/CIRCULATIONAHA.113.004305

20. Horlocker TT. Regional anaesthesia in the patient receiving antithrombotic and antiplatelet therapy. Br J Anaesth. 2011;107 Suppl 1:i96-106. doi:10.1093/bja/aer381 
21. Osta WA, Akbary H, Fuleihan SF. Epidural analgesia in vascular surgery patients actively taking clopidogrel. Br J Anaesth. 2010;104(4):429-32. doi:10.1093/bja/aeq029

22. Hodgson RE, Miller SM, Fortuna A, Harrison GR, Osta WA, Akbary $\mathrm{H}$ et al. Epidural analgesia in vascular surgery patients actively taking clopidogrel. Br J Anaesth. 2010;105(2):233. doi:10.1093/bja/aeq181

23. Kwok CS, Bulluck H, Ryding AD, Loke YK. Benefits and harms of extending the duration of dual antiplatelet therapy after percutaneous coronary intervention with drug-eluting stents: a meta-analysis. ScientificWorldJournal. 2014;2014:794078. doi:10.1155/2014/794078

24. Finkel JB, Marhefka GD, Weitz HH. Dual antiplatelet therapy with aspirin and clopidogrel: what is the risk in noncardiac surgery? A narrative review. Hosp Pract (1995). 2013;41(1):79-88. doi:10.3810/hp.2013.02.1013

25. Stone DH, Goodney PP, Schanzer A, Nolan BW, Adams JE, Powell $\mathrm{RJ}$ et al. Clopidogrel is not associated with major bleeding complications during peripheral arterial surgery. J Vasc Surg. 2011;54(3):779-84. doi:10.1016/j.jvs.2011.03.003

26. Paal P, Putz G, Gruber E, Le GT, Lemberger P. Subarachnoid hemorrhage after lumbar puncture in a patient receiving aspirin and clopidrogel. Anesth Analg. 2006;102(2):644-5. doi:10.1213/01.ANE.0000190738.50619.93

27. Horlocker TT, Wedel DJ, Benzon H, Brown DL, Enneking FK, Heit JA et al. Regional anesthesia in the anticoagulated patient: defining the risks (the second ASRA Consensus Conference on Neuraxial Anesthesia and Anticoagulation). Reg Anesth Pain Med. 2003;28(3):172-97.

28. Hirsh J, Anand SS, Halperin JL, Fuster V. Guide to anticoagulant therapy: Heparin : a statement for healthcare professionals from the American Heart Association. Circulation. 2001;103(24):2994-3018. doi:10.1161/01.CIR.103.24.2994

29. Hirsh J, Warkentin TE, Shaughnessy SG, Anand SS, Halperin JL, Raschke R et al. Heparin and low-molecular-weight heparin: mechanisms of action, pharmacokinetics, dosing, monitoring, efficacy, and safety. Chest. 2001;119(1 Suppl):64S-94. doi:10.1378/chest.119.1_suppl.64S

30. Ruff RL, Dougherty JH Jr. Complications of lumbar puncture followed by anticoagulation. Stroke. 1981;12(6):879-81. doi:10.1161/01.STR.12.6.879

31. Liu SS, Mulroy MF. Neuraxial anesthesia and analgesia in the presence of standard heparin. Reg Anesth Pain Med 1998;23(6 Suppl 2):157-63. doi:10.1016/S1098-7339(98)90142-0

32. Gogarten W, Vandermeulen E, Van Aken H, Kozek S, Llau JV, Samama CM. Regional anaesthesia and antithrombotic agents: recommendations of the European Society of Anaesthesiology. Eur J Anaesthesiol. 2010;27(12):999-1015. doi:10.1097/EJA.0b013e32833f6f6f

33. Owens EL, Kasten GW, Hessel EA 2nd. Spinal subarachnoid hematoma after lumbar puncture and heparinization: a case report, review of the literature, and discussion of anesthetic implications. Anesth Analg. 1986;65(11):1201-7. doi:10.1213/00000539-198611000-00018

34. Greaves JD. Serious spinal cord injury due to haematomyelia caused by spinal anaesthesia in a patient treated with low-dose heparin. Anaesthesia. 1997;52:150-4. doi:10.1111/j.1365-2044.1997.63-az0065.x

35. Sanderink GJ, Guimart CG, Ozoux ML, Jariwala NU, Shukla UA, Boutouyrie BX. Pharmacokinetics and pharmacodynamics of the prophylactic dose of enoxaparin once daily over 4 days in patients with renal impairment. Thromb Res. 2002;105(3):225-31. doi:10.1016/S0049-3848(02)00031-2

36. Horlocker TT, Wedel DJ. Neuraxial block and low-molecular-weight heparin: balancing perioperative analgesia and thromboprophylaxis.
Reg Anesth Pain Med. 1998;23(6 Suppl 2):164-77. doi:10.1016/S1098-7339(98)90143-2

37. Gurkanlar D, Acikbas C, Cengiz GK, Tuncer R. Lumbar epidural hematoma following lumbar puncture: the role of high dose LMWH and late surgery: a case report. Neurocirugia (Astur). 2007;18(1):52-5. doi:10.1016/S1130-1473(07)70312-3

38. Heit JA. Low-molecular-weight heparin: biochemistry, pharmacology, and concurrent drug precautions. Reg Anesth Pain Med. 1998;23(6 Suppl 2):135-9. doi:10.1016/S1098-7339(98)90138-9

39. Harter K, Levine M, Henderson SO. Anticoagulation drug therapy: a review. West J Emerg Med. 2015;16(1):11-7. doi:10.5811/westjem.2014.12.22933

40. Horton JD, Bushwick BM. Warfarin therapy: evolving strategies in anticoagulation. Am Fam Physician. 1999;59(3):635-46.

41. Vandermeulen E. Is anticoagulation and central neural blockade a safe combination? Curr Opin Anaesthesiol. 1999;12(5):539-43. doi: 10.1097/00001503-199910000-00009

42. Butler JJ. Use of low-dose prothrombin complex concentrate before lumbar puncture. Am J Health Syst Pharm. 2015;72(3):203-5. doi:10.2146/ajhp140310

43. Weitz Jl. Expanding use of new oral anticoagulants. F1000Prime Rep. 2014;6:93. doi:10.12703/P6-93

44. Stangier J, Rathgen K, Stähle H, Mazur D. Influence of renal impairment on the pharmacokinetics and pharmacodynamics of oral dabigatran etexilate: an open-label, parallel-group, single-centre study. Clin Pharmacokinet. 2010;49(4):259-68. doi:10.2165/11318170-000000000-00000

45. Benzon HT, Avram MJ, Green D, Bonow RO. New oral anticoagulants and regional anaesthesia. Br J Anaesth. 2013;111 Suppl 1:i96-113. doi:10.1093/bja/aet401

46. Baron TH, Kamath PS, McBane RD. Management of antithrombotic therapy in patients undergoing invasive procedures. N Engl J Med. 2013;368(22):2113-24. doi:10.1056/NEJMra1206531

47. Connolly G, Spyropoulos AC. Practical issues, limitations, and periprocedural management of the NOAC's. J Thromb Thrombolysis. 2013;36(2):212-22. doi:10.1007/s11239-013-0911-2

48. Liew A, Douketis J. Perioperative management of patients who are receiving a novel oral anticoagulant. Intern Emerg Med. 2013;8(6):477-84. doi:10.1007/s11739-013-0963-5

49. Samama MM. Which test to use to measure the anticoagulant effect of rivaroxaban: the anti-factor Xa assay. J Thromb Haemost. 2013;11(4):579-80. doi:10.1111/jth.12165

50. Weitz JI, Hirsh J, Samama MM. New antithrombotic drugs: American College of Chest Physicians evidence-based clinical practice guidelines (8th Edition). Chest. 2008;133(6 Suppl):234S-56S. doi:10.1378/chest.08-0673

51. Douketis JD, Spyropoulos AC, Kaatz S, Becker RC, Caprini JA, Dunn AS et al. Perioperative bridging anticoagulation in patients with atrial fibrillation. N Engl J Med. 2015;373(9):823-33. doi:10.1056/NEJMoa1501035

52. Lip GY, Nieuwlaat R, Pisters R, Lane DA, Crijns HJ. Refining clinical risk stratification for predicting stroke and thromboembolism in atrial fibrillation using a novel risk factor-based approach: the euro heart survey on atrial fibrillation. Chest. 2010;137(2):263-72. doi:10.1378/chest.09-1584

53. Cannegieter SC, Rosendaal FR, Briët E. Thromboembolic and bleeding complications in patients with mechanical heart valve prostheses. Circulation. 1994;89(2):635-41. doi:10.1161/01.CIR.89.2.635

54. Jong PG, Coppens M, Middeldorp S. Duration of anticoagulant therapy for venous thromboembolism: balancing benefits and harms on the long term. Br J Haematol. 2012;158(4):433-41. doi:10.1111/j.1365-2141.2012.09196.x 
55. Grines CL, Bonow RO, Casey DE Jr, Gardner TJ, Lockhart PB, Moliterno DJ et al. Prevention of premature discontinuation of dual antiplatelet therapy in patients with coronary artery stents: a science advisory from the American Heart Association, American College of Cardiology, Society for Cardiovascular Angiography and Interventions, American College of Surgeons, and American Dental Association, with representation from the American College of Physicians. J Am Coll Cardiol. 2007;49(6):734-9. doi:10.1016/j.jacc.2007.01.003

56. Jneid H, Anderson JL, Wright RS, Adams CD, Bridges CR, Casey DE Jr et al. 2012 ACCF/AHA focused update of the guideline for the management of patients with unstable angina/non-ST-elevation myocardial infarction (updating the 2007 guideline and replacing the 2011 focused update): a report of the American College of Cardiology Foundation/American Heart Association Task Force on Practice Guidelines. J Am Coll Cardiol. 2012;60(7):645-81. doi:10.1016/j.jacc.2012.06.004

57. Asdaghi N, Romano JG. Dual antiplatelet therapy in acute ischemic stroke. Curr Atheroscler Rep. 2015;17(7):37. doi:10.1007/s11883-015-0515-8

58. Hassell ME, Hildick-Smith D, Durand E, Kikkert WJ, Wiegerinck EM, Stabile E et al. Antiplatelet therapy following transcatheter aortic valve implantation. Heart 2015;101(14):1118-25. doi:10.1136/heartjnl-2014-307053 